Oral presentation

\title{
The calcaneocuboid joint moves with three degrees of freedom
} Thomas M Greiner*1 and Kevin A Ball ${ }^{2}$

\author{
Address: ${ }^{1}$ Department of Health Professions, University of Wisconsin - La Crosse, USA and ${ }^{2}$ Department of Physical Therapy, University of \\ Hartford, USA \\ Email: Thomas M Greiner* - greiner.thom@uwlax.edu \\ * Corresponding author
}

from Ist Congress of the International Foot \& Ankle Biomechanics (i-FAB) community

Bologna, Italy. 4-6 September 2008

Published: 26 September 2008

Journal of Foot and Ankle Research 2008, I(Suppl I):O39 doi:I0.I I86/I757-I I46-I-SI-O39

This abstract is available from: http://www.jfootankleres.com/content/I/SI/O39

(c) 2008 Greiner and Ball; licensee BioMed Central Ltd.

\section{Introduction}

Investigations of the calcaneocuboid joint typically find that it is among the least mobile of the intrinsic foot joints [1]. When movement is found, it is shown to be highly variable among individuals [2]. The joint is therefore relegated to the presumably rigid lateral aspect of the foot. The complementary articular surfaces of the two relevant bones are both relatively flat, with some irregular undulations. This joint surface geometry suggests that movement might be limited to a single rotation and perhaps superior and lateral translations in the synovial plane. In this presentation we challenge this expectation by exploring the calcaneocuboid joint in six degrees of freedom through multiple driving actions.

\section{Methods}

Data are derived from the legs of 12 non-pathological embalmed cadavers. Legs were prepared by removing all soft tissue, so that only ligamentous structures remained to sustain limb integrity. Each specimen was cycled by moving the leg on the foot through three mutually orthogonal driving actions (Inversion-Eversion, MedialLateral Rotation, and Plantarflexion-Dorsiflexion) while monitoring the relative positions of the calcaneus and cuboid with an active-marker tracking system. The Functional Alignment method [3] was used to derive joint axis orientations and motion patterns for three rotational and three translational degrees of freedom. These results are explored by plotting observed movement patterns against the percentage of the movement cycle.

\section{Results}

The movements of the calcaneocuboid joint were explored in all six degrees of freedom for all three driving actions. Figure 1 shows the three clearest movement patterns that were identified. In response to the inversioneversion driving action the cuboid rotates as much as $25^{\circ}$ about an oblique axis - a movement best described as obvolution-involution [4]. The same driving action also produces up to $2 \mathrm{~mm}$ of posterior-anterior translation an actual distraction of the synovial joint. The medial-lateral driving action produced a $6^{\circ}$ rotational response about a differently oriented oblique axis, in a movement best described as obversion-reversion [4]. No distinctive movements were produced as a response to the plantarflexion-dorsiflexion driving action.

\section{Conclusion}

The calcaneocuboid joint is more mobile than many conventional authorities would suggest. The joint was observed to move in three distinct ways. The largest rotation, occurring only in response to inversion-eversion, meets the expectations based upon surface geometry. However, the other two motions, which require some measure of joint distraction, are not obvious consequences of this geometry. 

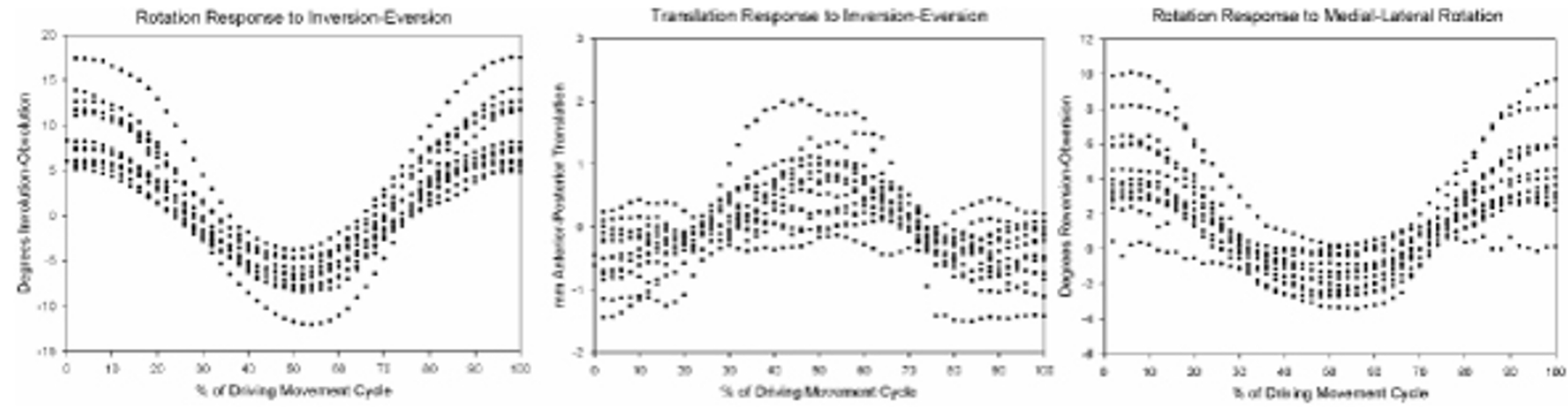

Figure I

The three movement patterns identified for the calcaneocuboid joint; a rotation and translation as the result of the inversioneversion driving motion and a rotation produced by the medial-lateral rotation of the leg on the foot.

\section{References}

I. Mattingly B, et al.: / Biomech 2006, 39:726-733.

2. Nester CH, et al.:J Biomech 2007, 40:1927-1937.

3. Ball KB, et al.: Proceedings of ISB 3D. Tampa, FL 2004.

4. Greiner TM: Foot Ankle Int 2007, 28:109-125.

Publish with Bio Med Central and every scientist can read your work free of charge

"BioMed Central will be the most significant development for disseminating the results of biomedical research in our lifetime. "

Sir Paul Nurse, Cancer Research UK

Your research papers will be:

- available free of charge to the entire biomedical community

- peer reviewed and published immediately upon acceptance

- cited in PubMed and archived on PubMed Central

- yours - you keep the copyright
BioMedcentral 